Gut, 1984, 25, 881-885

\title{
Factors influencing the healing rate of gastric ulcer in hospitalised subjects
}

\author{
M OKADA, T YAO, T FUCHIGAMI, K IMAMURA, AND T OMAE \\ From the Department of Internal Medicine II, Faculty of Medicine, Kyushu University, and Department of \\ Internal Medicine I, Faculty of Medicine, Fukuoka University, Japan
}

SUMMARY A multiple linear regression analysis was carried out on 75 inpatients with gastric ulcer. In order to elucidate the effects of various factors - endoscopic and roentgenological findings, age, sex, medical history, and drugs such as antacids, anticholinergics or both - on the healing rate, these factors were compared between those with ulcer which healed within eight weeks after treatment and those which did not. In patients over 50 years of age, alcohol consumption of over $60 \mathrm{~g}$ per day until admission, duration of present ulcer pain for over three months, single ulcer, ulcer located in the lesser curvature and uneven elevation around the ulcer, there was significant delaying effect on ulcer healing. Drug ingestion, sex, smoking habits until admission, size, depth, and shape of ulcer, coexisting gastritis, and past and family history of ulcer disease had no significant effect on healing after eight weeks. The patients with less than two unfavourable factors $(n=46)$ had the best healing rate $(100 \%)$ compared with those with three $(n=20)$ or four or more $(n=9)$ unfavourable factors. The healing rate of the latter two groups was $60 \%$ and $22 \%$, respectively $(p<0 \cdot 001)$. A prognostic score based on these six factors represents the severity of gastric ulcer disease with regard to the healing rate in patients prescribed antacids, and/or anticholinergic drugs.

The healing of gastric ulcer is influenced by drug therapy as well as by other factors. There are a number of controlled studies ${ }^{1-5}$ on the effect of various drugs on the healing rate of gastric ulcer, however, there is little documentation of the effects of factors other than drug treatment on the healing of gastric ulcer. The aim of the present study was to evaluate the effect of various factors such as medical history, endoscopic, and roentgenological findings, in addition to drug treatment on the healing of gastric ulcer under conditions of hospital admission.

\section{Methods}

PATIENTS

Eighty four Japanese patients with gastric ulcer admitted to our clinic from April 1976 to May 1978 were entered into the trial. The diagnosis was confirmed by both endoscopy and radiograph examination within 48 hours before the initiation of

\footnotetext{
Address for correspondence: M Okada, MD. Department of Internal Medicine II, Faculty of Medicine. Kyushu University. Maidashi 3-1-1. Higashi-ku. Fukuoka 812. Japan.

Received for publication 20 October 1983
}

treatment. Excluded from the study were pregnant women, patients with chronic liver or renal disease, or any other severe disease, patients regularly on acetylsalicylic acid or other ulcerogenic drugs, patients with a past history of ulcer surgery, and patients with pyloric or prepyloric ulcers. Informed consent was obtained from all patients.

The patients were randomly allocated to double blind treatment in three different groups. The order of the medications was randomised by a random number table into blocks of six patients.

Treatment started within 48 hours after endoscopy. All patients were treated as inpatients. As a rule, the patients got up at $7 \mathrm{am}$ and went to bed at $9 \mathrm{pm}$. The patients were permitted to walk within the hospital during the day, but were not allowed to go out of the hospital. One group (anticholinergic group) were given dicyclomine hydrochloride (Bentyl ${ }^{\circledR}$ ), $10 \mathrm{mg}$ three times a day, and $10 \mathrm{mg}$ at bedtime; a second group (antacid group) received dried aluminium hydroxide, $0.8 \mathrm{~g}$ three times a day, and $0.8 \mathrm{~g}$ at bedtime together with magnesia oxydum ponderosum, $0.4 \mathrm{~g}$ three times a day, and $0.4 \mathrm{~g}$ at bedtime (that is a buffering 
capacity of $200 \mathrm{mmol} / \mathrm{day})$; and a third group (antacid/anticholinergic group) received both an antacid and an anticholinergic, in the same dose as above. Thus, all patients had to swallow four tablets and four powders per day.

Endoscopy was repeated every two weeks until ulcer healing was confirmed. The ulcer was regarded as healed when complete epithelialisation of the ulcer was achieved, as determined by endoscopy. The patient was discharged from hospital when ulcer healing was confirmed. During the period of admission, each of these patients took the above medication. If the ulcer had not healed at eight weeks after treatment, however, other drugs such as cimetidine etc were given. Gastric biopsy was done in all patients at the beginning of the study and gastric cancer was ruled out in all. Ulcer size was assessed by the method of Doll and Pygott. ${ }^{6}$ In cases of multiple ulcers, the diameter of the largest ulcer was measured. Those ulcers whose base appeared to be almost on a level with the surrounding mucosa were called flat, and those with a clearly depressed base of more than 3 or $4 \mathrm{~mm}$ from the margin were called deep. The coexisting gastritis was classified as only a superficial or erosive gastritis.

The duration of the present ulcer pain was dated from the inception of the present ulcer like symptoms. The patients stopped drinking alcohol after admission and were ordered to stop smoking.

The following items were compared between those with ulcer which healed within eight weeks after treatment and those which did not: age, sex, duration of present ulcer symptoms, smoking and drinking habits before admission, family and past history of gastric ulcer, drug treatment, ulcer size, and endoscopic findings such as shape, depth, number and site of ulcer, gastritis, uneven elevation around the ulcer and folds' convergence.

The relationship of ulcer healing to the foregoing variables was first examined by using $\chi^{2}$ test with Yates' correction and unpaired Student's $t$ test, and subsequently by using multiple stepwise linear regression analysis ${ }^{7}$ in which healing within eight weeks was the dependent variable. All factors which were statistically unfavourable for gastric ulcer healing were weighed equally, and were used to calculate a prognostic score.

\section{Results}

Of the 84 patients, nine dropped out: six patients had been treated with dicyclomine hydrochloride, two with antacid, and one with antacid/anticholinergic. The reason for drop out was discharge at two weeks with the ulcer unhealed because of personal reasons. Thus, 75 patients ( 50 men and 25 women) were available for analysis of the healing within eight weeks after admission. Twenty seven had received antacids, 24 anticholinergics, and 24 antacid/anticholinergic. The ulcer healed in 60 of 75 $(80 \%)$ patients within eight weeks.

Table 1 shows various characteristics of patients with healed or unhealed gastric ulcers. Among these characteristics, age was of significant importance for the healing rate - that is, patients over 50 years old had a significantly poorer healing rate. The present period of ulcer pain and alcohol ingestion had some effect on the healing rate, but the values did not reach the threshold of significance. Within eight weeks, the ulcer healed in 23 of the antacid group $(85.2 \%), 17$ of the anticholinergic group $(70 \cdot 8 \%)$, and 20 of the antacid/anticholinergic group (83.3\%). These differences were not significant. The sex, smoking habits, and family and past history of gastric ulcer did not correlate with the healing rate.

Among the endoscopic and roentgenological findings, an ulcer size of over $20 \mathrm{~mm}$ and uneven elevation around the ulcer had a significant delaying

Table 1 Characteristics of patients with healed $(n=60)$ and non-healed $(n=15)$ gastric ulcer

\begin{tabular}{|c|c|c|c|}
\hline & \multicolumn{2}{|c|}{ Gastric ulcer } & \multirow[b]{2}{*}{$\begin{array}{l}\text { Signifi- } \\
\text { cance }\end{array}$} \\
\hline & Healed $^{*}$ & $\begin{array}{l}\text { Non- } \\
\text { healedt }\end{array}$ & \\
\hline \multicolumn{4}{|l|}{$\operatorname{Agc}(y r)$} \\
\hline Mean & $48 \cdot 3 \pm 15 \cdot 8$ & $57 \cdot 9 \pm 10 \cdot 8$ & \multirow{3}{*}{$\begin{array}{l}\mathrm{p}<0 .(05 \\
\mathrm{p}<0 .(05\end{array}$} \\
\hline$<50$ & 32 & 3 & \\
\hline$\geqslant 50$ & 28 & 12 & \\
\hline \multicolumn{4}{|l|}{ Sex } \\
\hline Male & 42 & 8 & \multirow{2}{*}{ NS } \\
\hline Femalc & 18 & 7 & \\
\hline \multicolumn{4}{|l|}{$\begin{array}{l}\text { Duration of present ulcer } \\
\text { symptoms (months) }\end{array}$} \\
\hline$<3$ & 50 & 9 & \multirow{2}{*}{$p=0.11$} \\
\hline$\geqslant 3$ & 10 & 6 & \\
\hline \multicolumn{4}{|l|}{ Cigarette smokers $(\geqslant 10 /$ day $)$} \\
\hline Yes & 35 & 8 & \multirow{2}{*}{ NS } \\
\hline No & 25 & 7 & \\
\hline \multirow{2}{*}{\multicolumn{4}{|c|}{$\begin{array}{l}\text { Alcohol consumption } \\
\text { over } 60 \mathrm{~g} / \text { day }\end{array}$}} \\
\hline & & & \\
\hline Yes & 7 & 5 & \multirow{2}{*}{$p=0 \cdot 10$} \\
\hline No & 53 & 10 & \\
\hline \multicolumn{4}{|c|}{ Family history of gastric ulcer } \\
\hline Yes & 2 & 1 & \multirow{2}{*}{ NS } \\
\hline No & 58 & 14 & \\
\hline \multicolumn{4}{|l|}{ Past history of gastric ulcer } \\
\hline Yes & 6 & 3 & \multirow{2}{*}{ NS } \\
\hline No & 54 & 12 & \\
\hline \multicolumn{4}{|l|}{ Treatment } \\
\hline Antacid & 23 & 4 & \multirow{3}{*}{ NS } \\
\hline Anticholinergic & 17 & 7 & \\
\hline Antacid/anticholinergic & 20 & 4 & \\
\hline
\end{tabular}


effect on healing (Table 2). Single ulcer or ulcer located in the lesser curvature healed less rapidly, but the differences were not significant. Shape, depth, site such as body or angle, gastritis, or folds' convergence had no effect on the healing rate.

Table 3 shows the results of a multiple stepwise linear regression analysis. The following six factors had a significant delaying effect on healing: age over 50 years $(p<0 \cdot 01)$, alcohol consumption of over $60 \mathrm{~g}$ per day $(p<0.01)$, ulcer located in the lesser curvature $(p<0 \cdot 01)$, single ulcer $(p<0 \cdot 05)$, duration of present ulcer pain for over three months $(p<0.05)$, and uneven elevation around the ulcer $(p<0 \cdot 05)$. When these factors were taken into account, other factors such as drug, the sex, and ulcer size etc were not significant.

The scoring system was one in which each unfavourable factor was given equal weight. The patients with varying numbers of a total of six unfavourable factors were classified into five groups (Table 4). With the increment of the prognostic score, the healing rate decreased from 100\% (score

Table 2 Characteristics of endoscopic findings in healed $(n=60)$ and non-healed $(n=15)$ gastric ulcer patients

\begin{tabular}{|c|c|c|c|}
\hline & \multicolumn{2}{|c|}{ Gastric ulcer } & \multirow[b]{2}{*}{$\begin{array}{l}\text { Signifi- } \\
\text { cance }\end{array}$} \\
\hline & Healed* & $\begin{array}{l}\text { Non- } \\
\text { healed }{ }^{+}\end{array}$ & \\
\hline \multicolumn{4}{|l|}{ Ulcer shape } \\
\hline Round or oval & 45 & 12 & \multirow{2}{*}{ NS } \\
\hline Irregular & 15 & $3 \quad\}$ & \\
\hline Ulcer size (mm) & $16 \cdot 5 \pm 7 \cdot 1$ & $23 \cdot 1 \pm 11 \cdot 9$ & $\mathrm{p}<0 \cdot 05$ \\
\hline$<20$ & 43 & $6 \quad\}$ & \multirow{2}{*}{$\mathrm{p}<0 \cdot 05$} \\
\hline$\geqslant 20$ & 17 & 9 & \\
\hline \multicolumn{4}{|l|}{ Ulcer depth } \\
\hline $\begin{array}{l}\text { Flat } \\
\text { Decp }\end{array}$ & 12 & $\begin{array}{r}1 \\
14\end{array}$ & NS \\
\hline \multicolumn{4}{|l|}{ Numbers of ulcers } \\
\hline Single & 38 & 13 & \multirow{2}{*}{$\begin{array}{l}\text { NS } \\
(p=() \cdot 15)\end{array}$} \\
\hline Multiple & 22 & 2 & \\
\hline \multicolumn{4}{|l|}{ Site (A) } \\
\hline Body & 33 & 6 & \multirow{2}{*}{ NS } \\
\hline Angle & 27 & 9 & \\
\hline \multicolumn{4}{|l|}{ Site (B) } \\
\hline Lesser curvature & 32 & 12 & \multirow{2}{*}{$\begin{array}{l}\text { NS } \\
(p=0 \cdot 11)\end{array}$} \\
\hline Others & 28 & 3 & \\
\hline \multicolumn{4}{|l|}{ Gastritis } \\
\hline Yes & 6 & 3 & \multirow{2}{*}{ NS } \\
\hline No & 54 & 12 & \\
\hline \multicolumn{4}{|c|}{$\begin{array}{l}\text { Uneven elevation around } \\
\text { the ulcer }\end{array}$} \\
\hline Yes & 5 & 5 & \multirow{2}{*}{$\mathrm{p}<0.05$} \\
\hline No & 55 & 10 & \\
\hline \multicolumn{4}{|l|}{ Folds' convergence } \\
\hline Yes & 29 & 7 & \multirow{2}{*}{ NS } \\
\hline No & 31 & 8 & \\
\hline
\end{tabular}

of 1 to 2 ) to $60 \%$ (score of 3 ) and $22.2 \%$ (score of 4 to 5$)(\mathrm{p}<0 \cdot 001)$.

\section{Discussion}

All but one ${ }^{9}$ of previously reported studies on factors influencing the healing of gastric ulcer involved an univariate analysis. As various factors influencing the healing of gastric ulcer are often interrelated, such an analysis may be inadequate. To clarify factors influencing the healing, the association between the healing and a single factor should be examined taking into account the various factors. A multivariate analysis is suitable for the purpose, as the relative importance of various factors in association with healing can be evaluated.

Slower healing in older patients has been observed by other workers, ${ }^{10-12}$ though there were exceptions. ${ }^{13-15}$ Nakajima $^{9}$ noted in a multivariate analysis that age was a significant factor influencing gastric ulcer healing, which agrees with our observations. Sonnenberg et al $^{16}$ also recently reported a slower healing in such patients with duodenal ulcer. This is also the case with other reparative processes such as wound healing and healing of bone fractures. ${ }^{17-19}$

It is worth noting that alcohol consumption of over $60 \mathrm{~g}$ per day up to admission had a significant delaying effect on ulcer healing. This finding has not been reported, though there are data that alcohol is not a risk factor of gastric ulcer. ${ }^{20}$ Sonnenberg and coworkers ${ }^{16}$ found that moderate drinking promotes ulcer healing in outpatients with duodenal ulcer. This finding may be explained by recent studies that prostaglandins are formed endogenously by administration of mild irritants such as low concentrations of alcohol and necrosis of the gastric mucosa is prevented.$^{21}$ In our study, alcohol consumption of over $60 \mathrm{~g}$ per day - not a mild irritant - may bring about direct damage to gastric mucosa and the rate of healing would be slow. It is generally accepted that smoking delays the healing of duodenal ulcer. ${ }^{101322} 23$ Concerning the effect of smoking on the healing of gastric ulcer, however, the results obtained have been conflicting. ${ }^{10} 1322$ We found that smoking up to admission had no direct effect on gastric ulcer healing. As a rule, our patients stopped smoking after admission. Thus, the association between the amount of tobacco smoked after admission and ulcer healing was not a factor to be considered in this study.

In cases of duodenal ulcer, duration of present ulcer pain for more than three weeks had a significant delaying effect on ulcer healing. ${ }^{23}$ Similarly, in the present study, a long duration of present ulcer pain had a significant delaying effect 
Table 3 Multiple stepwise regression analysis of factors related to ulcer healing within eight weeks after treatment

\begin{tabular}{lllrl}
\hline $\begin{array}{l}\text { Step } \\
\text { no }\end{array}$ & Factor & Unfavourable & Fvalue & $R^{2}$ \\
\hline 1 & Elevation around the ulcer & Uneven & $4 \cdot 687^{*}$ & $0 \cdot 0865$ \\
2 & Age & Over 50 & $16 \cdot 913+$ & $0 \cdot 1622$ \\
3 & Alcohol consumption & Over 60 g/day & $7 \cdot 743+$ & $0 \cdot 2384$ \\
4 & Dicyclomine HCL & Intake & $3 \cdot 500$ & $0 \cdot 2990$ \\
5 & Site (B) & Lesser curvature & $8 \cdot 546^{+}$ & $0 \cdot 3548$ \\
6 & Duration of present ulcer symptoms & More than three months & $6 \cdot 315^{*}$ & $0 \cdot 4340$ \\
7 & No of ulcers & Single & $6 \cdot 349^{*}$ & $0 \cdot 4863$ \\
8 & Ulcer size & More than $20 \mathrm{~mm}$ & $2 \cdot 697$ & $0 \cdot 5310$ \\
\hline
\end{tabular}

${ }^{*} \mathrm{p}<0.05+\mathrm{p}<0.01$.

Percentage of variation accounted for $=R^{2} \times 100 . R=$ multiple correlation.

on gastric ulcer healing. In patients with a short period of pain, the ulcer would be diagnosed early and be treated early after the onset in order and rapid healing would follow. On the contrary, in patients with a long period of pain, the ulcer would be diagnosed later and be treated later after the onset and the healing would be slow.

Among the endoscopic data, single ulcer, ulcer located in the lesser curvature, and uneven elevation around the ulcer had a significant delaying effect on ulcer healing, while shape and depth of ulcer and gastritis had no significant effect on the healing after eight weeks. Uneven elevation around the ulcer appears to indicate submucosal fibrosis as a result of a repetition of recurrence. The reason why single ulcer and ulcer located in the lesser curvature tend to heal slowly is difficult to explain. Previous studies $^{9} 11{ }^{14}$ showed that large gastric ulcers healed more slowly than small ulcers. In our study, size had a significant effect on ulcer healing in the univariate analysis, but an insignificant effect in the multivariate analysis. This may be explained by the relationship between the ulcer size and other factors such as age $(r=0.232, p<0.05)$, site $B(r=-0.300$, $\mathrm{p}<0.05$ ), and duration of present ulcer symptoms $(\mathrm{r}=0.236, \mathrm{p}<0.05)$.

In conclusion, the six factors such as age over 50 years, alcohol consumption of over $60 \mathrm{~g}$ per day up

Table 4 Gastric ulcer healing within eight weeks after treatment by number of unfavourable factors $(n=75)$

\begin{tabular}{llrrrrrrr}
\hline \multicolumn{1}{l}{ Score } \\
\cline { 2 - 8 } Patients with & 0 & 1 & 2 & 3 & 4 & 5 & 6 \\
\hline Healed ulcer & $/$ & 15 & 31 & 12 & 2 & 0 & $/$ \\
Non-healed ulcer & $/$ & 0 & 0 & 8 & 6 & 1 & $/$ \\
\hline p $<0.001$. & & & & & & &
\end{tabular}

to admission, duration of present ulcer pain for over three months, ulcer located in the lesser curvature, single ulcer, and uneven elevation around the ulcer had a significant delaying effect on healing of gastric ulcer. The greater the number of these six unfavourable factors in a patient, the less likely the ulcer is to heal. Further prospective studies should confirm reliability of these factors in affecting the healing process under conventional medical treatment in patients with gastric ulcer.

\section{Addendum}

The reliability of the effect of these six unfavourable factors on the healing rate of gastric ulcer has been confirmed in a prospective study of 60 consecutive cases admitted to our clinic from April 1980 to December 1982. These patients were given antacids, anticholinergics, or both. The criteria to enter the study were the same as conditions used in the first series. The ulcer was completely healed in 43 patients (healing rate $71 \cdot 1 \%$ ). Depending upon the number of unfavourable factors present, the healing rate within eight weeks after treatment is shown in the addendum Table. The greater the number of these unfavourable factors in a patient, the less expectation there was for healing. These results indicate the importance of these factors in the

Addendum Table Gastric ulcer healing within eight weeks after treatment by number of unfavourable factors $(n=60)$

\begin{tabular}{|c|c|c|c|c|c|c|c|}
\hline \multirow[b]{2}{*}{ Patients with } & \multicolumn{7}{|c|}{ Score* } \\
\hline & 0 & 1 & 2 & 3 & 4 & 5 & 6 \\
\hline Healed ulcer & 2 & 7 & 22 & 9 & 3 & 0 & 0 \\
\hline Unhealed ulcer & 0 & 0 & 0 & 5 & 7 & 4 & 1 \\
\hline
\end{tabular}


healing process of gastric ulcer, under conventional medical treatment such as antacids, anticholinergics, or both.

Gratitude is extended to M Ohara for comments on the manuscript and to $\mathrm{K}$ Yamada for technical assistance.

\section{References}

1 Sutton DR. Gastric ulcer healing with tripotassium dicitrato bismuthate and subsequent relapse. Gut 1982 ; 23: 621-4.

2 Ciclitira PJ, Machell RJ, Farthing MJG, Dick AP, Hunter JO. Double-blind controlled trial of cimetidine in the healing of gastric ulcer. Gut 1979; 20: 730-4.

3 Taylor RH, Laidlow JM. Chapman RG et al. Doubleblind trial comparing cimetidine with carbenozolone in the treatment of benign gastric ulcer. [Abstract] Gut 1977; 18: A420.

4 Butler ML, Gersh H. Antacid vs placebo in hospitalized gastric ulcer patients. A controlled therapeutic study. Am J Dig Dis 1975: 20: 8()3-7.

5 Baume PE, Hunt JH, Piper DW. Glycopyrronium bromide in the treatment of chronic gastric ulcer. Gastroenterology 1972; 63: 399-406.

6 Doll R, Pygott F. Factors influencing the rate of healing of gastric ulcers. Admission to hospital, phenobarbitone, and ascorbic acid. Lancet 1952: 1: 171-5.

7 Snedecor GW, Cochraw WG. Statistical methods. 6th ed. Ames, Iowa: Iowa State University Press, 1967: 381-446.

8 Nie NN, Hull CH, Jenkins JG, Steinbrenner K. Dent DH. Statistical package for the social sciences. New York: McGraw-Hill, 1975.

9 Nakajima T. Studies on factors affecting healing of gastric ulcer. Am J Gastroenterol 1976; 66: 150-4.
10 Piper DW, Hunt J, Heap TR. The healing rate of chronic gastric ulcer in patients admitted to hospital. Scand J Gastroenterol 1980; 15: 113-7.

11 Steigman F, Schulman B. The time of healing of gastric ulcers: implications as to therapy. Gastroenterology 1952; 20: 20-6.

12 Bockus HL. Perspective and prognosis in peptic ulcer. In: Bockus HL, ed. Gastroenterology vol 1. Philadelphia, London, Toronto: W B Saunders, 1974: 938-48.

13 Hermann RP, Piper DW. Factors influencing the healing rate of chronic gastric ulcer. Am J Dig Dis 1973; 18: 1-6.

14 Grossman MI. The veterans administration cooperative study on gastric ulcer. Resumé and comment. Gastroenterology 1971; 61: 635-8.

15 Pollard HM, Bachrach WH, Block M. The rate of healing of gastric ulcers. Gastroenterology 1947; 8: 435-7.

16 Sonnenberg A, Müller-Lissner SA, Vogel E et al. Predictors of duodenal ulcer healing and relapse. Gastroenterology 1981; 81: 1061-7.

17 Binstock RH, Shanas E. Handbook of aging and the social sciences. New York: Van Nostrand Reinhold Company, 1976.

18 Brocklehurst JG. Textbook of geriatric medicine and gerontology. Edinburgh, London: Churchill Livingstone, 1973.

19 Reichel W. Clinical aspects of aging. Baltimore: Williams and Wilkins, 1978.

20 Piper DW, McIntosh JH, Greig M, Shy CM. Environmental factors and chronic gastric ulcer. Scand J Gastroenterol 1982; 17: 721-9.

21 Robert A. Cytoprotection by prostaglandins. Gastroenterology 1979; 77: 761-7.

22 Doll R, Jones FA, Pygott F. Effect of smoking on the production and maintenance of gastric and duodenal ulcers. Lancet 1958; 1: 657-62.

23 Massarrat S, Eisenmann A. Factors affecting the healing rate of duodenal and pyloric ulcers with low-dose antacid treatment. Gut 1981; 22: 97-102. 